\title{
Experimental Analysis of the Universal Continuous Digging Machine Working Processes
}

Juraj Gerlici ${ }^{1}$, Volodymyr Musiiko ${ }^{2}$, Andrii Koval ${ }^{2}$, Volodymyr Nikolaenko ${ }^{2}$, Jurii Lazaruk ${ }^{2}$, Tomas Lack ${ }^{1}$, Kateryna Kravchenko ${ }^{1}$

${ }^{1}$ Faculty of Mechanical Engineering, University of Zilina. Univerzitná 8215/1, 01026 Zilina. Slovak Republic.

E-mail: juraj.gerlici@fstroj.uniza.sk, tomas.lack@fstroj.uniza.sk, kkatherina@ukr.net

${ }^{2}$ Faculty of Automotive and Mechanical Engineering, National Transport University. M. Omelianovicha-Pavlenka, 1,01010 Kiev. Ukraine.E-mail:musvd@i.ua, kandr@i.ua, nikvolja@hotmail.com, layuvo@ukr.net

The article presents the results of experimental research on creating the mobile continuous earthmoving machinery. Methods for performing field experimental studies and measuring equipment used are described. The article shows the data of experimental research, their analysis, the determination of physical nature of changes in external load characteristics of the machinery operating equipment. The conducted experimental studies of modern mobile earthmoving machinery enabled to establish its technical capabilities, the characteristics of the power load of the operating equipment when developing the soil. It also enabled to determine the ways and directions for modernizing the operating equipment of machinery. One of the ways is to optimize technological combination of soil cutting, displacement of the developed soil to the unloading area and unloading of the actuator. The research performed and the results obtained have enabled to experimentally confirm the effectiveness of the technical proposals to create the design of the chain and bar actuators with impulse soil unloading intensifiers for trenchers implemented in the industry.

Keywords: Tensometric System, Recording Equipment, Torque and Driveshaft Rotation Speed Sensor, Hydraulic Fluid Pressure Sensor

\section{Introduction}

Earthwork, especially in the field of transport construction, involves the development and displacement of billions of cubic meters of soil. Such work is possible only with the use of high-performance earthmoving machinery, first of all continuous excavators. They can quickly and efficiently construct trenches for various purposes, canals, drainage systems in reclamation construction, oil and gas transportation and gas distribution systems. The use of excavators for longitudinal digging for this purpose can greatly improve the efficiency of work and thus increase the speed of constructing engineering facilities for various purposes. The performance of specialized excavators is 3-4 times greater than universal excavators of cyclic action of equal weight. The use of such machinery is extremely important when fortificating the positions of troops and covers for military equipment.

Thus, expanding the scope of use of excavators for longitudinal digging, improving the technical and operational performance of their work fully meets the modern requirements of scientific and technological advance and the creation of new technologies.

Trenchers are specific machinery that simultaneously cut the soil, remove it from the trench and lay it outside the area of the constructed trench in a given place.

Given that in the future, the actuators of the continuous excavators will be mechanical systems that destroy the soil by cutting or digging, the knowledge of the physical bases and patterns of these processes will enable to create effective and reliable machinery.

Thus, the creation of highly efficient structures of actuators for continuous earthmoving machinery is possible only if the physical features of the actuator interaction with the developed environment are taken into account when designing the actuators.

In view of the above-mentioned, it is expedient to carry out the research and identify the problematic issues. They involve the physical features of the work processes of chain and bar actuators of the continuous earthmoving machinery. Using the obtained results, it is necessary to develop technical proposals for creating actuator innovative structures of excavators for longitudinal digging.

2 The peculiarities of work processes of universal continuous earthmoving machinery

A vehicle as a mechanical system is exposed to loading $[1,2,3,4,5]$. Scientific and technical papers, patents and copyright certificates $[6,7,8]$ outline the results of studies of operating equipment effectiveness 
of continuous earthmoving machinery. The analysis of these publications shows that there are a number of unsolved issues regarding high efficiency of soil development and the quality of excavation when constructing engineering objects [9]. In this regard, great scientific and practical interest provokes solving the problem of effective technological combination of different processes in the actuator of continuous earthmoving machinery. They involve soil development processes, transportation of soil from the face by the actuator, unloading it from the actuator and laying it in the breastwork with minimal power consumption of the machinery power plant.

The processes of soil development, creating effective structures of the actuators and drives of the continuous earthmoving machinery, the efficiency of unloading the actuators were investigated in $[10,11$, 12] and others. They are still extremely relevant nowadays.

In recent years, scientists of many scientific and educational institutions, including National Transport University (NTU), have dealt with the problems of improving soil development by chain actuators of the earthmoving machinery: V.D. Musiyko, A.B. Koval; M.K. Sukach (KNUCA); S.V. Kravets (NUWM) Ukraine; A. Ya. Kotlobay (Belarusian National Technical University) - Belarus; V.S. Shcherbakov, M.Ye. Agapov (Siberian State Automobile and Road Academy) - Russian Federation, and others [13, 14, 15, 16].

Notwithstanding the above-mentioned, the problem of creating high performance continuous earthmoving machinery that meet these requirements remains urgent.

Both rotary (bucket and non-bucket) and chain (bucket and chain and bar) actuators are used as operating equipment in the continuous earthmoving machinery $[17,18]$.

\section{Experimental research of mobile ma- chinery}

To solve the problem of determining the efficiency and feasibility of using chain and bar soil development equipment in the universal trencher, full-scale tensometric testing of the prototype sample of the PZM-301 modernized regimental earthmoving machinery was carried out.

In comparison with the PZM-2 and PZM-3, the peculiarity of the PZM-3-01 earthmoving machinery is that in order to provide the required technical and operating characteristics, namely: performance, maneuverability, durability, reliability and transportability, the machinery is made using a KrAZ-5233HE automotive chassis. The operating equipment of the PZM3-01 earthmoving machinery is similar in design to PZM-2 and PZM-3, Fig. 1. It consists of a non-bucket chain and bar soil development actuator (see Fig. 1). It is adapted for digging trenches (position 1) and ditches (position 2) in frozen and non-frozen soils of categories I - IV. Ditch digging is carried out in the mode of reciprocating feed of the operating equipment of the machinery to the face (see Fig. 1).

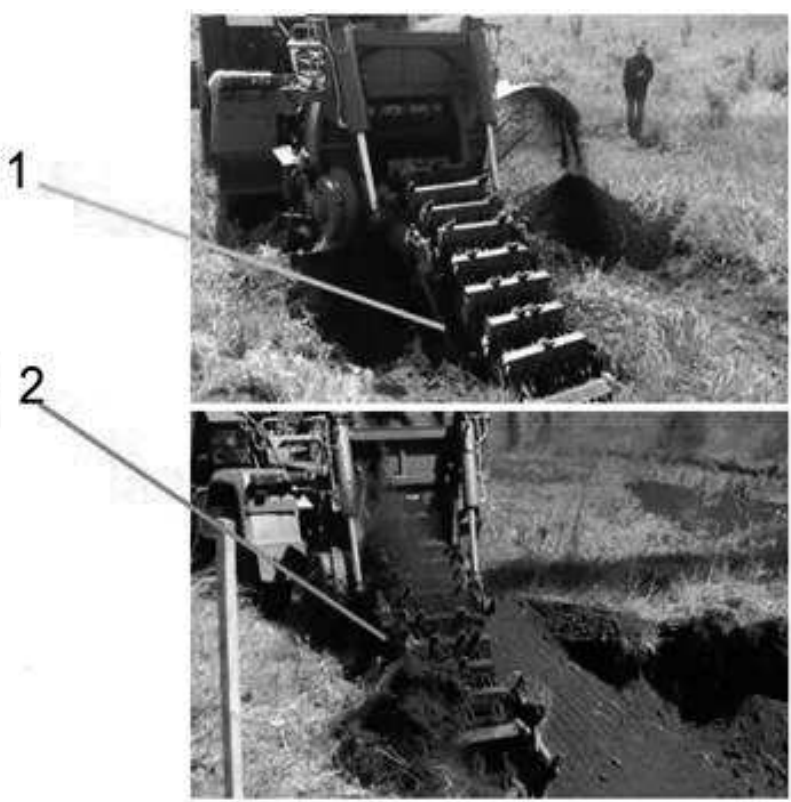

Fig. 1 The position of the actuator during the operation: 1 - in the process of trenching; 2 - in the process of ditch digging

To place the developed soil outside the constructed excavation, a driving thrower is installed in the machinery.
The use of a basic chassis of the KrAZ-5233HE is due to the modern requirements for ensuring the ne- 
cessary speeds of the machinery movement. In particular, it concerns the speed of the machinery as it moves in the military column.

Soil development is carried out by a chain and bar actuator, the placement of the developed soil into a dump is carried out by a rotary thrower with centrifugal unloading. This provides compact soil placement in the breastwork, both when trenching and ditch digging.

In the course of the research, it became necessary to unambiguously solve the problem of forming and minimizing external loads on the chain and bar actuators. Besides, there appeared a need to clarify the method for calculating external loads and to determine the required drive power of operating equipment. It was also necessary to distribute the power between soil development machinery, evacuation machinery

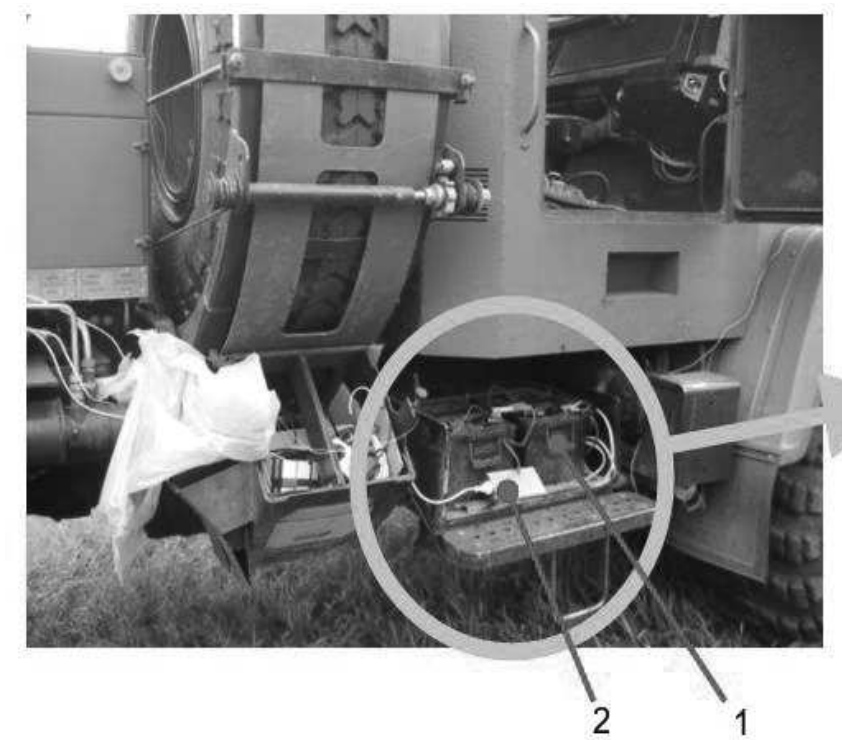

and mechanism drive of the machinery movement.

To determine the power load of the earthmoving machinery when digging the soil, to evaluate the efficiency of the drives and the machinery as a whole, to identify the physical features of work processes, experimental tensometric testing of the earthmoving machinery was carried out using the following equipment:

- tensometric system and recording equipment (Fig. 2);

- torque sensor and driveshaft rotation speed of the operating equipment (Fig. 3);

- pressure sensors of hydraulic fluid in hydropipelines (Fig. 4);

- $\quad$ speed sensor of the machinery movement.

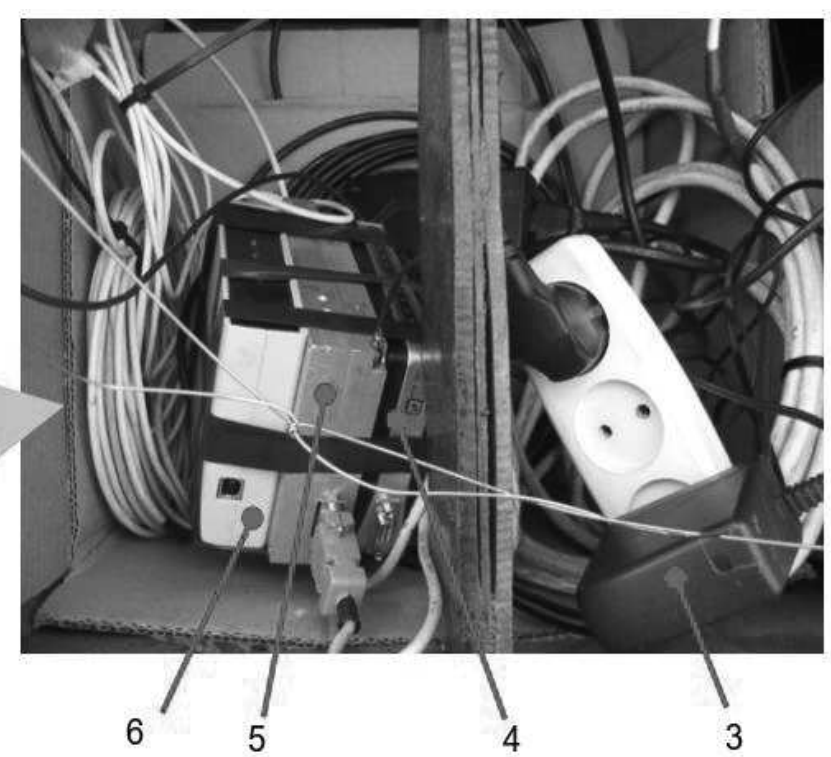

Fig. 2 Tensometric system and recording equipment installed in the macbinery during testing: 1 - battery of the base vebicle; 2 voltage converter -24 V/ 220V;3 - power supply;4 -D-Link DIR-320 router; 5 - ADC; 6 - tensometric station

A typical oscillogram for changing the torque value on the driveshaft of the machinery operating equipment when digging the soil is presented in Fig. 5.

The analysis of the PZM-3-01 tensometric testing results confirmed the ability of the machinery to dig in the soils of category II $(\mathrm{Cb}=8)$ the trenches with a depth of $1.1-1.4 \mathrm{~m}$, a width at the bottom of $0.65 \mathrm{~m}$, on the top of $0.9 \mathrm{~m}$ with the performance up to 324 run.m $/ \mathrm{h}\left(237 \mathrm{~m}^{3} / \mathrm{h}\right)$ for one pass of the machinery and ditches with a width of $3.6 \mathrm{~m}$ in the mode of reciprocating feed of the actuator to a face with the performance of 47.6 run.m $/ \mathrm{h}\left(145.8 \mathrm{~m}^{3} / \mathrm{h}\right)$ with a depth of $3 \mathrm{~m}$ for three passes of the machinery. In the mode of maximum performance of constructing trenches of the specified cross profile by the PZM-3-01 machinery the power within 196-223 $\mathrm{kW}$ is used.

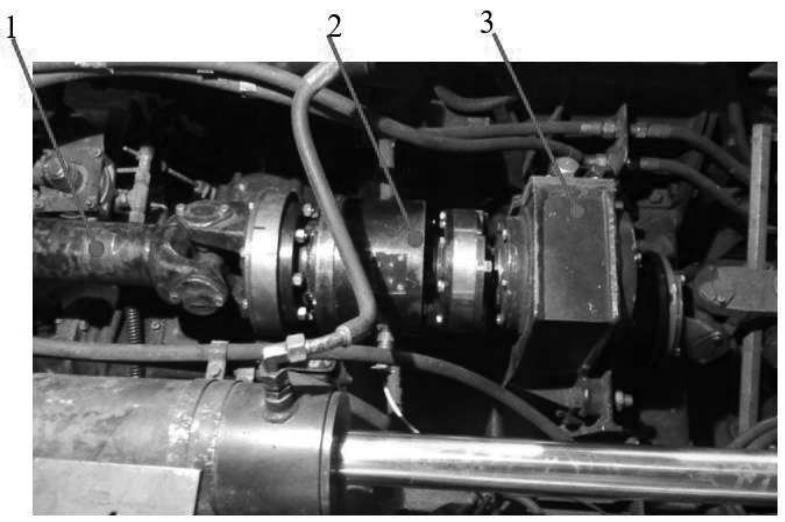

Fig. 3 The torque and driveshaft rotation speed sensor of the machinery operating equipment: 1 - driveshaft; 2 - torque and rotation speed sensor; 3 -power takeoff gearbox 

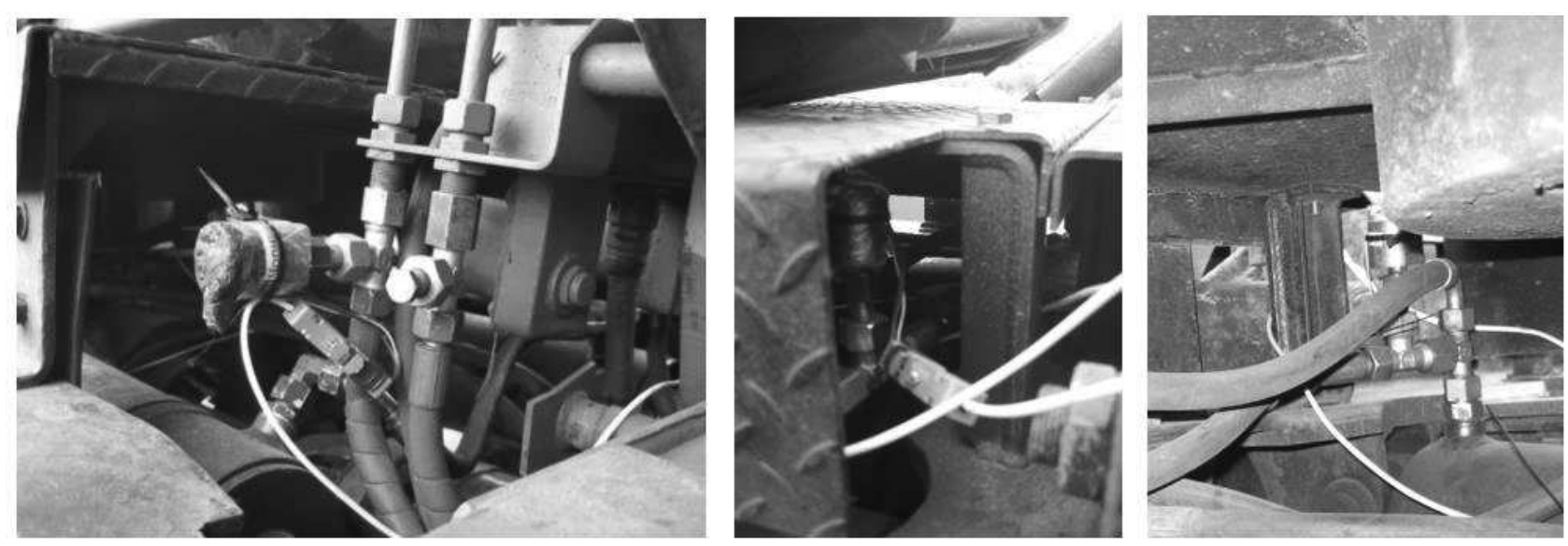

Fig. 4 Hydraulic fluid pressure sensors mounted in the machinery

A typical oscillogram for changing the torque value on the driveshaft of the machinery operating equipment when digging the soil is presented in Fig. 5.

The analysis of the PZM-3-01 tensometric testing results confirmed the ability of the machinery to dig in the soils of category II $(\mathrm{Cb}=8)$ the trenches with a depth of $1.1-1.4 \mathrm{~m}$, a width at the bottom of $0.65 \mathrm{~m}$, on the top of $0.9 \mathrm{~m}$ with the performance up to 324 run.m $/ \mathrm{h}\left(237 \mathrm{~m}^{3} / \mathrm{h}\right)$ for one pass of the machinery and ditches with a width of $3.6 \mathrm{~m}$ in the mode of reciprocating feed of the actuator to a face with the performance of 47.6 run.m $/ \mathrm{h}\left(145.8 \mathrm{~m}^{3} / \mathrm{h}\right)$ with a depth of $3 \mathrm{~m}$ for three passes of the machinery. In the mode of maximum performance of constructing trenches of the specified cross profile by the PZM-3-01 machinery the power within $196-223 \mathrm{~kW}$ is used.
In the mode of constructing ditches, the performance of excavation is determined by the carrying capacity of the actuator which operates in the mode of reciprocating feed to the face. It is expected to be 2 times less than in the trench mode.

Thus, the power used reaches $124 \mathrm{~kW}$. When digging trenches, the maximum fixed driving force of the machinery reaches $58 \mathrm{kN}$. The torque on the driveshaft of the operating equipment is up to $1270 \mathrm{~N} \cdot \mathrm{m}$. The total reactive force in the hydraulic cylinders of lifting-lowering the operating equipment is $5.6 \mathrm{kN}$. Residual soil spills at the bottom of the trench range from $0.20 \mathrm{~m}$ to $0.35 \mathrm{~m}$ (without the use of a protective grating of the thrower included in the machinery design). The energy intensity of the soil development of category II is $0.4 \mathrm{~kW} \cdot \mathrm{h} / \mathrm{m}^{3}-0.43 \mathrm{~kW} \cdot \mathrm{h} / \mathrm{m}^{3}$ at the trench digging with a depth of $1.25 \mathrm{~m}$.

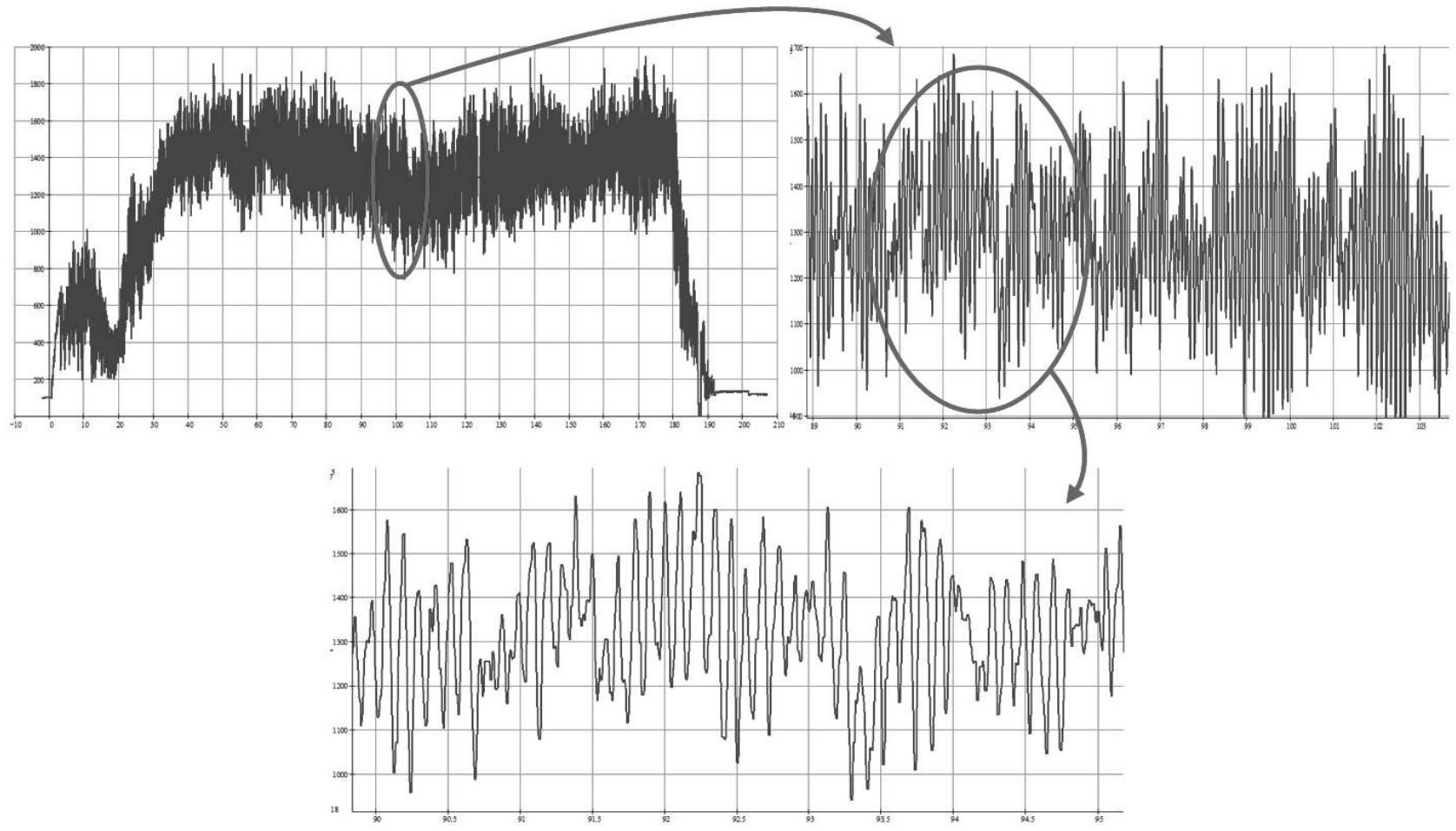

Fig. 5 Typical torque measurement oscillogram on the driveshaft of the operating equipment: (a) - the experiment lasting 200 seconds, (b) - part of the experiment lasting 14 seconds, (c) - part of the experiment lasting 5 seconds 
In the excavation mode, the torque on the driveshaft of the operating equipment changes cyclically in the range from $300 \mathrm{~N} \cdot \mathrm{m}$ to $720 \mathrm{~N} \cdot \mathrm{m}$, the driving force for moving the machinery reaches $24.6 \mathrm{kN}$. Residual soil spills at the bottom of the ditch occur and reach $0.10 \mathrm{~m}-0.15 \mathrm{~m}$ near the side walls of the excavation.

The results obtained during the studies in the first approximation indicate that in the mode of maximum performance of excavation, the power consumption of the engine is $228.45 \mathrm{~kW}$. It is close to the value of its rated power.

The analysis of the PZM-3-01 tensometric testing results confirmed the ability of the machinery to dig in the soils of category II $(\mathrm{Cb}=8)$ the trenches with a depth of $1.1-1.4 \mathrm{~m}$, a width at the bottom of $0.65 \mathrm{~m}$, on the top of $0.9 \mathrm{~m}$ with the performance up to 324 run.m/h $\left(237 \mathrm{~m}^{3} / \mathrm{h}\right)$ for one pass of the machinery and ditches with a width of $3.6 \mathrm{~m}$ in the mode of reciprocating feed of the actuator to a face with the performance of 47.6 run.m $/ \mathrm{h}\left(145.8 \mathrm{~m}^{3} / \mathrm{h}\right)$ with a depth of $3 \mathrm{~m}$ for three passes of the machinery. In the mode of maximum performance of constructing trenches of the specified cross profile by the PZM-3-01 machinery the power within $196 \mathrm{~kW}-223 \mathrm{~kW}$ is used.

In the mode of constructing ditches, the performance of excavation is determined by the carrying capacity of the actuator which operates in the mode of reciprocating feed to the face. It is expected to be 2 times less than in the trench mode.

Thus, the power used reaches $124 \mathrm{~kW}$. When digging trenches, the maximum fixed driving force of the machinery reaches $58 \mathrm{kN}$. The torque on the driveshaft of the operating equipment is up to $1270 \mathrm{~N} \cdot \mathrm{m}$. The total reactive force in the hydraulic cylinders of lifting-lowering the operating equipment is $5.6 \mathrm{kN}$. Residual soil spills at the bottom of the trench range from $0.20 \mathrm{~m}$ to $0.35 \mathrm{~m}$ (without the use of a protective grating of the thrower included in the machinery design). The energy intensity of the soil development of category II is $0.4 \mathrm{~kW} \cdot \mathrm{h} / \mathrm{m}^{3}-0.43 \mathrm{~kW} \cdot \mathrm{h} / \mathrm{m}^{3}$ at the trench digging with a depth of $1.25 \mathrm{~m}$.

In the excavation mode, the torque on the driveshaft of the operating equipment changes cyclically in the range from $300 \mathrm{~N} \cdot \mathrm{m}$ to $720 \mathrm{~N} \cdot \mathrm{m}$, the driving force for moving the machinery reaches $24.6 \mathrm{kN}$. Residual soil spills at the bottom of the ditch occur and reach $0.10 \mathrm{~m}-0.15 \mathrm{~m}$ near the side walls of the excavation.

The results obtained during the studies in the first approximation indicate that in the mode of maximum performance of excavation, the power consumption of the engine is $228.45 \mathrm{~kW}$. It is close to the value of its rated power.

According to experimental studies, the presence of significant residual spills at the bottom of trenches or ditches should be considered unacceptable. Reducing the performance of the machinery compared to the theoretically possible 2 times in the mode when the operating equipment performs a reciprocal movement in the face is also unacceptable. Significant energy consumption of the soil development by the actuator is inadmissible as well.

The results of experimental studies contradict theoretical calculations. This is, first of all, due to the significant repeated transfer of the developed soil back into the trench. It is a result of not sufficiently efficient unloading of the actuator from the transported soil. It is evidenced by the significant residual sills at the bottom of the excavations in the soil made by the actuator. Moreover, the transfer of the developed soil into the trench causes an increase in the power load on the drive of the actuator.

The way to solve this problem when digging the soil, is to ensure a secured separation of the soil developed and transported from the face from the transportation surfaces of the actuator and the removal of this soil beyond the contours of the actuator and profile in the excavation under construction.

We have proposed, investigated and implemented in industrial designs of the actuators of the continuous earthmoving machinery a method of unloading the soil. It involves the provision that the transported soil gets additional and sufficient impulse of forces at the moment of unloading. It is necessary to ensure both soil separation from the transportation surfaces of the actuator and its subsequent movement [8].

The implementation of impulse intensification of soil from a chain and bar actuator is possible with the following prerequisites:

-traction chains of the actuator are chains of onesided bend [9] consisting of separate units of special construction connected by hinges;

-at the radius section of its displacement (driving asterisk), the bigger the distance passed by the individual points of each link of the traction chain the greater the radius of curvature of the trajectory of movement of this point. By linking the determined points of the adjacent links of the traction chain (s) with a flexible link, it can be stated that when passing the radial section of the trajectory the flexible link will be fully straightened, Fig. 6. The acceleration of centrifugal movement of the middle point of the flexible link, the value of which is determined by the frequency of rotation of the driving asterisk of the traction chain, the radius of its dividing circle, the number of teeth of the driving asterisk, the linear dimensions of the links of the chain and the scheme of fastening the flexible link to the links of the traction chain. A spatial structure can be used as a flexible link. It is a web formed by articulated links of cargo chains (such as chain bottoms of buckets of rotor trenchers) with the original attachment of this web to adjacent links of traction chains (see Fig. 6). The web thus plays the role of the transportation surface for the developed soil. At the moment of soil collection takes the form of a bucket. 
During its "instantaneous" opening in the unloading area of the actuator, the mass of soil concentrated on this surface is given a force impulse directed from the center of the driveshaft rotation of the actuator. The radius vector of the force pulse applied to the soil mass centered on the surface of the transportation web is in the angular sector of the driving asterisk, between its first and second teeth engaged with the traction chain. The position of the radius vector determines the location of the evacuator developed by the actuator of the soil beyond the constructed excavation.

The opening of a flexible rectangular web when transporting the developed soil is conditioned by attaching its one side to the crossbar of the U-shaped transportation bar at the maximum possible distance from the axis of driveshaft rotation. The other side is attached to the previous traction chain link in the direction of the traction chain movement (Fig. 6).

Estimating the effect of impulse intensification of unloading the chain and bar actuator with mounted flexible transportation surfaces, the fact is taken into account that the whole mass of the developed soil, which is transported for unloading by a single flexible surface, is an elementary volume. It is concentrated in one point and is affected by the gravitation force of the soil, the coupling and the friction on the transportation surface. The inertia force applied to the mass of the elementary volume is determined by the "instantaneous" opening of this surface.

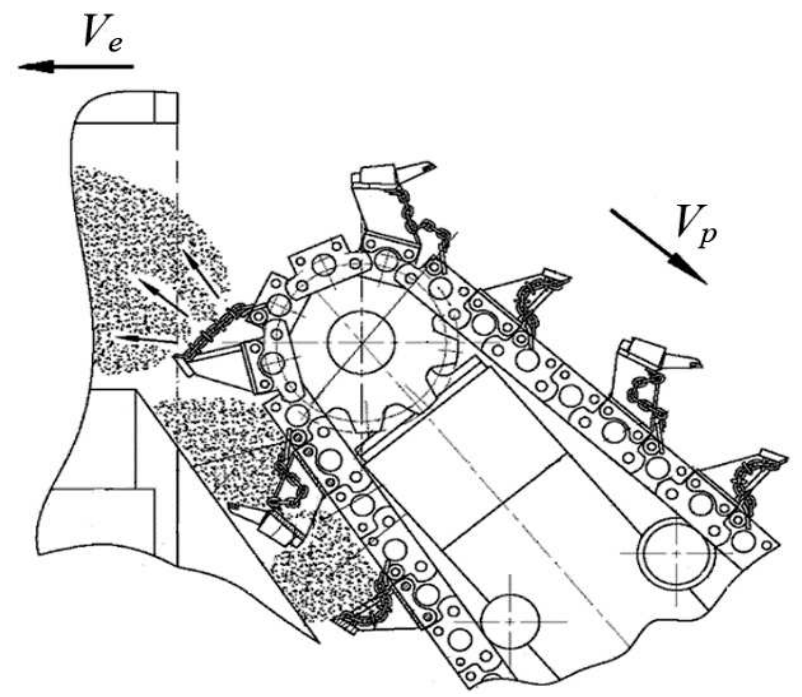

Fig. 6 A scheme of impulse unloading of chain and bar actuator

\section{Conclusions}

Universal continuous earthmoving machinery with a chain and bar actuator is a powerful and efficient technical means to solve complex engineering problems of earthwork in transport construction. The conducted experimental studies of modern mobile earthmoving machinery enabled to establish its technical capabilities, the characteristics of the power load of the operating equipment when developing the soil. It also enabled to determine the ways and directions for modernizing the operating equipment of machinery. One of the ways is to optimize technological combination of soil cutting, displacement of the developed soil to the unloading area and unloading of the actuator.

The authors have proposed, investigated and implemented in industrial designs of the actuators of the continuous earthmoving machinery a method for unloading by providing the transported soil additional and sufficient impulse of forces at the moment of unloading. It ensures the soil separation from the transportation surfaces of the actuator and its subsequent movement.

\section{References}

[1] DIŽO, J., BLATNICKÝ, M. (2019). Investigation of ride properties of a three-wheeled electric vehicle in terms of driving safety. In: Transportation Research Procedia 40, pp. 663-670. ISBN 23521457

[2] BARAN, P., ŠASTNIAK, P. KUKUČA, P., BREZÁNI, M. (2018). Investigation of kinematic parameters of two nonconventional piston machines with wobble board. In: MATEC Web of Conferences 157, (14 March 2018, 02003, 22nd Slovak-Polish Scientific Conference on Machine Modelling and Simulations, MMS 2017; Sklene Teplice; Slovakia). ISSN 2261236X

[3] SAKHNO, V., POLIAKOV, V., TIMKOV, O., KRAVCHENKO, O. (2016). Lorry convoy stability taking into account the skew of semitrailer axes. In: Transport Problems 11(3), pp. 6976. ISSN 18960596

[4] KURCIK, P., BLATNICKY, M., DIZO, J. (2019). Functional calculation of a driving mechanism of a handling machine for disabled persons. In: Manufacturing Technology 19(3), pp. 455-460. ISBN 12132489

[5] BLATNICKÁ, M., BLATNICKÝ, M., DIŽO, J., SÁGA, M. (2018). Comparison of analytical stress analysis and numerical calculation of mobile work machine part. In: Manufacturing Technology 18(2), pp. 190-192. ISBN 12132489

[6] DOMBROWSKI, M.G. Bucket Excavators. (1972). Construction, theory and calculation. Engineering, 432 p. Moscow.

[7] KRAVETS, S.V., KOVANKO, V.V., LUK'YANCHUK, O.P. (2015). Scientific bases of creation of earth-tier machines and underground mobile 
devices. Monograph. 322 p. The National University of Water and Environmental Engineering, Rivne, Ukraine.

[8] MUSIYKO, V.D. (2018). Theory and Creation of Innovative Continuous Earthmoving Machines. Monograph. 282 p. Kyiv: Lyudmila Publishing House.

[9] BYKOV, A.V. (1986). The study of the structural and kinematic parameters of the chain-beam working body of a universal digging machine. Ph.D. thesis, Kharkov National Automobile and Highway University.

[10] GARBUZOV, Z.E., ILGISONIS, V.K., MUTUSHEV, G.A. [et al.] (1965). Continuousaction earth-moving machinery. Engineering. 276 p. Moscow.

[11] VETROV, YU. A. (1971). Soil cutting by earthmoving machinery. Engineering, 360 p. Moscow.

[12] FEDOROV, D.I. (1977). Working bodies of earthmoving machinery. Engineering, 288 p. Moscow.

[13] KOVAL, A.B. (2014). Determination of Conditions for Ensuring the Course Stability of Universal Earthmoving Machines, 218 p. National University of Transport.

[14] KRAVETS, S.V., CANT, O.V., GAPONOV, R.O., YANCHIK, T.O. (2019). Visiting date of the line and the road of the transport scraper in the lance-scraper trench excavator. In: Collection of scientific papers. Construction. Materials Science. Engineering. Intensification of work processes of construction and road machines. Series: Hoisting-and-transport, construction and road machines and equipment 107. State Higher Educational Institution "PGASA", pp. 66-74.

[15] ACHANOV, M.E., (2013). Interaction of the working body of a trench excavator with soil in the transverse plane. In: Vestnik 5 (33), pp. 7 9. Siberian State Automobile and Highway University. ISSN 2658-5626

[16] KOTLOBAY, A. YA. et al. (2013). Formation of modernization directions for earthmoving machinery. In: Minsk: Science and technology 5, pp. 54-60. ISSN 2414-0392

[17] MUSIYKO, V.D., BLACKSMITH, A.B. (2014). Improvement of Trench Excavator with Trenchless Rotary Working Body. In: Collection of scientific works of the Ukrainian State Academy of Railway Transport 148 (1). Ukrainian State Academy of Railway Transport, 2014), pp. 4954. ISSN 2413-3795

[18] SHKOLNY, A.N. (2006). Rationale for the selection of design and technological parameters of the executive body of bucket-free chain trenchers, 23 p. Tomsk state university of architecture and building, Tomsk. 